\title{
Risk Factors for Mortality in Children with Congenital Heart Disease Delivered at a Brazilian Tertiary Center
}

Luciane Alves Rocha', MD; Sthefane Catib Froio' ${ }^{1}, \mathrm{MD}$; Célia Camelo Silva ${ }^{2}, \mathrm{MD}, \mathrm{PhD}$; Simone de Araujo Negreiros Figueira ${ }^{3}, \mathrm{MD}$; José Cícero Stocco Guilhen ${ }^{4}, \mathrm{MD}, \mathrm{PhD}$; Ruth Guinsburg ${ }^{3}$, MD, PhD; Edward Araujo Júnior ${ }^{1}$, MD, $\mathrm{MSc}, \mathrm{PhD}$

DOI: $10.21470 / 1678-9741-2018-0174$

\begin{abstract}
Objective: This study aims to investigate the incidence of postnatal diagnosis of congenital heart disease (CHD) and the predictive factors for hospital mortality.

Methods: This retrospective cohort study was conducted at a Brazilian tertiary center, and data were collected from medical records with inclusion criteria defined as any newborn with CHD diagnosed in the postnatal period delivered between 2015 and 2017. Univariate and multivariate analyses were performed to determine the potential risk factors for mortality.

Results: During the 3-year period, 119 (5.3\%) children of the 2215 children delivered at our institution were diagnosed with CHD. We considered birth weight $(P=0.005), 1^{\text {st }}$ min Apgar score $(P=0.001)$, and CHD complexity $(P=0.013)$ as independent risk factors
\end{abstract}

for in-hospital mortality. The most common CHD was ventricular septal defect. Indeed, $60.5 \%$ cases were considered as "complex" or "significant" CHDs. Heart surgeries were performed on $38.9 \%$ children, 15 of whom had "complex" or "significant" CHD. A mortality rate of $42 \%$ was observed in this cohort, with $28 \%$ occurring within the initial $24 \mathrm{~h}$ after delivery and $38 \%$ occurring in patients admitted for heart surgery.

Conclusion: The postnatal incidence of CHD at our service was $5.3 \%$. Low $1^{\text {st }}$ min Apgar score, low birth weight, and CHD complexity were the independent factors that affected the hospital outcome.

Keywords: Risk Factors. Heart Defects, Congenital. Infant, Newborn. Mortality.

\begin{tabular}{ll}
\hline Abbreviations, acronyms \& symbols \\
\hline CHD & $=$ Congenital heart disease \\
ECMO & $=$ Extracorporeal membrane oxygenation \\
EPM-UNIFESP $=$ Paulista School of Medicine, Federal University & of São Paulo \\
RACHS & Risk adjustment for congenital heart surgery \\
\hline
\end{tabular}

\section{INTRODUCTION}

Congenital heart diseases (CHDs), the leading abnormalities in fetuses, are six times more common than chromosomal abnormalities and four times more common than neural tube defects ${ }^{[1]}$. The incidence of CHD with intrauterine diagnosis ranges from $2.4 \%$ to $54 \%{ }^{[2-7]}$. However, some countries witness high incidence of CHD possibly due to the implementation of an organized policy to perform ultrasound heart screening ${ }^{[8-10]}$. In Brazil, CHDs are the main cause of death among infants with congenital abnormality, and the implementation of health public policies targeting such population may decrease infant mortality, as occurred in developed countries ${ }^{[11]}$.

A comprehensive assessment of the fetal heart optimizes the diagnosis of $\mathrm{CHD}$, offering appropriate prenatal and postnatal planning and facilitating an improvement in neonatal morbidity and surgical outcome ${ }^{[10,12-17]}$. Newborns with postnatal diagnosis could have unfavorable outcomes because symptoms and cardiovascular impairment may develop at home or in a community hospital, further increasing the morbidity and mortality rates.

Previously, a few studies focused on surgical and hospital outcomes ${ }^{[9]}$, encouraging us to document our experience with newborns with CHD at our service. Thus, the aim of our study
'Discipline of Fetal Medicine, Department of Obstetrics, Escola Paulista de Medicina da Universidade Federal de São Paulo (EPM-UNIFESP), São Paulo, SP, Brazil.

${ }^{2}$ Discipline of Cardiology, Department of Medical Clinic, Escola Paulista de Medicina da Universidade Federal de São Paulo (EPM-UNIFESP), São Paulo, SP, Brazil.

${ }^{3}$ Discipline of Neonatology, Department of Pediatrics, Escola Paulista de Medicina da Universidade Federal de São Paulo (EPM-UNIFESP), São Paulo, SP, Brazil.

${ }^{4}$ Discipline of Cardiovascular Surgery, Department of Surgery, Escola Paulista de Medicina da Universidade Federal de Sao Paulo (EPM-UNIFESP), Sao Paulo, SP, Brazil.
No financial support

No conflict of interest

Correspondence Address:

Edward Araujo Júnior

Rua Belchior de Azevedo, 156, apto. 111 - Torre Vitoria - São Paulo, SP, Brazil - Zip

Code: 05089-030

E-mail: araujojred@terra.com.br 
was to define the current postnatal incidence of $\mathrm{CHD}$ at one Brazilian referral center and to determine the risk factors that may affect the hospital outcome.

\section{METHODS}

This historical cohort study was conducted at one referral center [São Paulo Hospital at Paulista School of Medicine, Federal University of São Paulo (EPM-UNIFESP, São Paulo, Brazil)] having expertise in fetal and pediatric echocardiography and critical care for complex CHDs in Southeast Brazil, however, without extracorporeal membrane oxygenation (ECMO).

Data were collected from the medical records of pregnant women and their newborns diagnosed with CHD. The study protocol was approved by the Ethics Committee of UNIFESP.

In this study, the inclusion criteria were newborns with postnatal diagnosis of CHD delivered at our service between January 2015 and December 2017, regardless of the center where the prenatal follow-up was conducted. Patients with inadequate echocardiographic data were excluded from the final analysis. We used the classification system of fetal heart diseases based on the complexity of anatomical heart abnormalities ${ }^{[18,19]}$. "Complex CHDs" included heterotaxy or atrial isomerism, atresia or severe hypoplasia of a valve or chamber (hypoplastic left heart syndrome, pulmonary atresia, tricuspid atresia, aortic atresia, mitral atresia, and Ebstein's anomaly), and abnormalities of the valve inlet or outlet (complete atrioventricular septal defect, truncus arteriosus, double inlet left or right ventricle, and double outlet left or right ventricle congenitally corrected transposition of the great arteries). "Significant CHDs" included transposition of the great vessels, tetralogy of Fallot, large ventricular septal defect, coarctation of the aorta, aortopulmonary window, critical aortic or pulmonary stenosis, partial atrioventricular septal defect, total anomalous pulmonary venous connection, and tricuspid valve dysplasia (no Ebstein's anomaly). "Minor CHDs" included small ventricular septal defect and less severe aortic or pulmonary stenosis, whereas dysrhythmias, cardiomyopathies, secondary dextrocardia/levocardia, pulmonary sequestration, and patent ductus arteriosus were classified as "other CHDs" $[18,19]$.

Furthermore, newborns were categorized undergoing surgery depending on the study of risk adjustment for in-hospital mortality of children undergoing congenital heart surgery (designated as RACHS - Risk adjustment for congenital heart surgery) $)^{[20]}$. RACHS can be used in the comparative assessment of outcomes among institutions to guide quality improvement efforts. In this study, independent variables included gestational age at delivery (weeks), birth weight (g), prematurity, $1^{1 \text { st }}$ and $5^{\text {th }}$ min Apgar score, karyotype analysis, presence of extracardiac malformations, type of delivery, type of CHD, clinical and surgical treatments for CHD, need for mechanical ventilation, antibiotics, and vasoactive drugs, and the dependent variable was hospital mortality.

Means and standard deviations were calculated for quantitative variables, and percentage and absolute values were described for qualitative variables. Subsequently, an inferential analysis of the study variables was conducted. The unpaired Student's t-test was used for quantitative variables and chi-square or Fisher's exact test for qualitative variables. For all analyses, $P$-values of $<0.05$ was considered statistically significant.
All baseline variables with univariate analysis exhibiting $P<0.10$ were selected for logistic regression analysis.

The analyses were performed using the program STATA/ IC 12.1 (College Station, TX, USA) for MacBook (Apple Inc., Cupertino, CA, USA).

\section{RESULTS}

During the 3-year study period, 2215 children were born at our institution, of whom 119 (5.3\%) were diagnosed with CHD, and no child was excluded in this study. Table 1 summarizes the study population, stating that the prenatal diagnosis of $\mathrm{CHD}$ was $84.8 \%$.

The mean maternal age was $30 \pm 7.9$ years, and $31.5 \%$ were aged $\geq 35$ years. The mean gestational age at delivery was $36 \pm 5$ (range, 34-39) weeks. Approximately $31 \%$ children were prematurely born, and $47 \%$ had low birth weight. In addition, neurological disorders (48.8\%) were found to be the most common malformations associated with $\mathrm{CHD}$, and trisomy 21

Table 1. Baseline characteristics of patients $(n=119)$.

\begin{tabular}{|c|c|}
\hline Variables & \\
\hline Maternal age in years, mean \pm SD & $30 \pm 7.9$ \\
\hline Maternal age $\geq 35$ years, $\mathrm{n}(\%)$ & $36(31.5)$ \\
\hline Prenatal diagnosis of CHD, n (\%) & $101(84.8)$ \\
\hline Gestational age at delivery in weeks, mean \pm SD & $36.8 \pm 2.7$ \\
\hline Prematurity, n (\%) & $38(31.9)$ \\
\hline Cesarean, n (\%) & $83(69.7)$ \\
\hline Birth weight in gram, mean \pm SD & $2512 \pm 789$ \\
\hline Birth weight $\leq 2500 \mathrm{~g}, \mathrm{n}(\%)$ & $56(47)$ \\
\hline $1^{\text {st }}$ min Apgar score, mean $\pm S D$ & $6.4 \pm 2$ \\
\hline $5^{\text {th }}$ min Apgar score, mean $\pm S D$ & $7.8 \pm 2$ \\
\hline Multiple fetal malformations, n (\%) & $65(54)$ \\
\hline Neurological system & 26 \\
\hline Facial & 17 \\
\hline Respiratory system & 3 \\
\hline Gastrointestinal tract & 9 \\
\hline Genital & 3 \\
\hline Abdominal & 7 \\
\hline Urinary tract & 9 \\
\hline Arms and limbs & 24 \\
\hline Chromosomal abnormalities, n (\%) & $32(26.8)$ \\
\hline Trisomy 21 & 12 \\
\hline Trisomy 18 & 11 \\
\hline Trisomy 13 & 7 \\
\hline Others & 2 \\
\hline
\end{tabular}

$\mathrm{CHD}=$ congenital heart disease; $\mathrm{SD}=$ standard deviation 
(37.5\%) and trisomy 18 (34.3\%) were the leading chromosomal abnormalities.

We considered 72 (60.5\%) cases as "complex" and "significant" according to the classification system of CHDs based on the complexity of anatomical heart abnormalities. Our study reported ventricular septal defect to be the most common CHD (Table 2). In the delivery room, resuscitation was conducted in $36.1 \%$ of the children; of these, $14.3 \%$ required intubation. Most children needed mechanical ventilation and vasoactive drugs during hospitalization (59.7\% and 50.3\%, respectively). Furthermore, heart surgery was performed in $38.9 \%$ of the children (Table 3 ).

Figure 1 shows the frequency of surgical cases based on the study of risk adjustment for in-hospital mortality of children after undergoing surgery for CHD (designated RACHS). In addition,

Table 2. Congenital heart disease by the classification system according to the complexity of anatomical heart abnormalities $(n=119)$.

\begin{tabular}{|c|c|}
\hline Congenital heart disease & $\begin{array}{l}\text { Frequency } \\
\text { (n) }\end{array}$ \\
\hline Complex & 51 \\
\hline Heterotaxy or atrial isomerism & 2 \\
\hline Hypoplastic left heart syndrome & 11 \\
\hline Pulmonary atresia & 8 \\
\hline Tricuspid atresia & 2 \\
\hline Ebstein's anomaly & 2 \\
\hline Truncus arteriosus & 2 \\
\hline Complete atrioventricular septal defect & 17 \\
\hline Double outlet of right ventricle & 6 \\
\hline Ectopia cordis & 1 \\
\hline Significant & 21 \\
\hline Tetralogy of Fallot & 6 \\
\hline Transposition of the great vessels & 2 \\
\hline Critical pulmonary stenosis & 1 \\
\hline Coarctation of the aorta & 11 \\
\hline $\begin{array}{l}\text { Total anomalous pulmonary venous } \\
\text { connection }\end{array}$ & 1 \\
\hline Minor & 40 \\
\hline Small ventricular septal defect & 28 \\
\hline Atrial septal defect & 11 \\
\hline Less severe pulmonary stenosis & 1 \\
\hline Others & 7 \\
\hline Cardiomyopathies & 1 \\
\hline Secondary dextrocardia/levocardia & 3 \\
\hline Persistent ductus arteriosus & 3 \\
\hline
\end{tabular}

Table 3. Interventions performed in the study population $(n=119)$

\begin{tabular}{l|c}
\hline Variables & $\mathbf{N}(\%)$ \\
\hline Resuscitation in the delivery room, $\mathrm{n}(\%)$ & $43(36.1)$ \\
\hline Positive pressure ventilation, $\mathrm{n}(\%)$ & $42(35.3)$ \\
\hline Intubation in the delivery room, $\mathrm{n}(\%)$ & $17(14.3)$ \\
\hline Mechanical ventilation, $\mathrm{n}(\%)$ & $71(59.7)$ \\
\hline Parenteral nutrition, $\mathrm{n}(\%)$ & $56(47)$ \\
\hline Cardiac surgery, $\mathrm{n}(\%)$ & $46(38.9)$ \\
\hline Antibiotics, $\mathrm{n}(\%)$ & $27(23)$ \\
\hline Vasoactive drug, $\mathrm{n}(\%)$ & $59(50.3)$ \\
\hline
\end{tabular}

mortality can be observed for each risk category. The highest mortality rate was observed in category 6 (66.7\%). Among the patients admitted for surgery but who died, a tendency of correlation with the complexity of the disease was noted $(P=0.08)$.

Mortality was observed in $42 \%$ cases $(n=50)$, of which 14 (28\%) occurred within the initial 24 hours after delivery, and the average time of death was 19 days. In addition, 18 (38\%) cases of death were recorded among patients admitted for heart surgery, 15 of whom had a "complex" or "significant" CHD. Because variables such as weight, prenatal diagnosis, $1^{\text {st }}$ min Apgar score, chromosomal abnormalities, and CHD complexity correlate with mortality $(P<0.10)$ in the univariate analysis, they were selected for logistic regression. Finally, we considered low birth weight $(P=0.005)$, low $1^{\text {st }}$ min Apgar score $(P=0.001)$, and CHD complexity $(P=0.013)$ as independent risk factors for hospital mortality (Table 4).

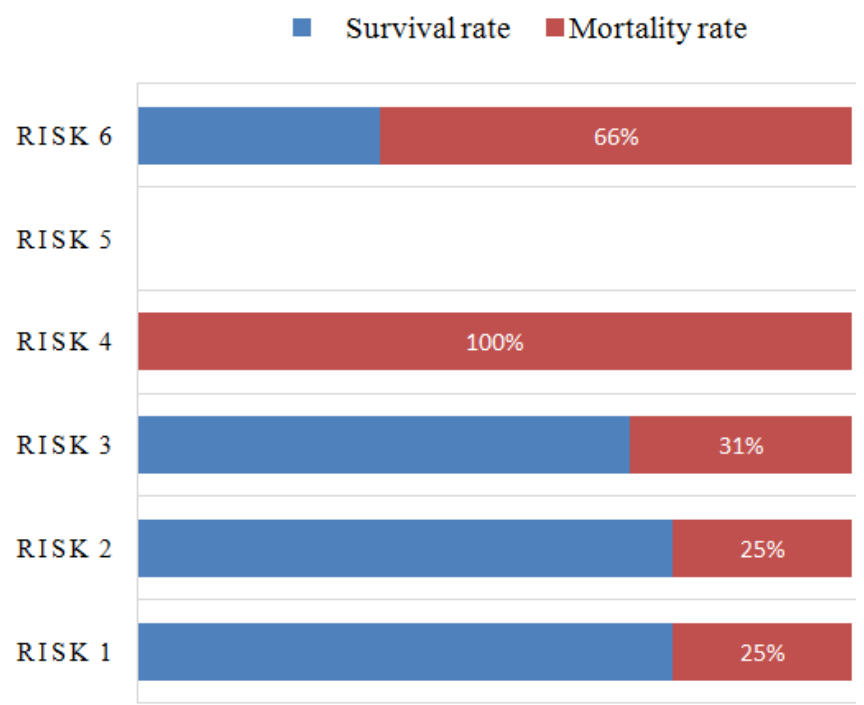

Fig. 1 - The frequency of surgical cases and mortality based on the study RACHS $(n=46)$. 
Table 4. Mortality rates in the study population and associated factors $(n=50)$.

\begin{tabular}{|c|c|c|}
\hline Variables & Death & $P$ \\
\hline Maternal age in years, mean \pm SD & $30.6 \pm 7.1$ & $0.49^{(1)}$ \\
\hline Gestational age at delivery in weeks, mean \pm SD & $36.4 \pm 3.3$ & $0.22^{(1)}$ \\
\hline Prematurity, n (\%) & $16(32)$ & $0.98^{(2)}$ \\
\hline Birth weight in gram, mean \pm SD & $2228.5 \pm 863$ & $0.0007^{(1) / /^{*}}$ \\
\hline Prenatal diagnosis, n (\%) & $47(94)$ & $0.02^{(2) /(*)}$ \\
\hline Cesarean, n (\%) & $37(74)$ & $0.39^{(2)}$ \\
\hline $1^{\text {st }}$ min Apgar score, mean $\pm S D$ & $6.4 \pm 2$ & $<0.0001^{(1) /(*)}$ \\
\hline Multiple fetal malformations, n (\%) & $29(58)$ & $0.34^{(2)}$ \\
\hline Chromosomal abnormalities, n (\%) & $18(36)$ & $0.08^{(2) /(*)}$ \\
\hline Complexity of the $\mathrm{CHD}, \mathrm{n}(\%)$ & & $0.08^{(3) /(*)}$ \\
\hline Complex & $28(56)$ & \\
\hline Significant & $7(14)$ & \\
\hline Minor & $12(24)$ & \\
\hline Others & $3(6)$ & \\
\hline
\end{tabular}

(1)Student's t-test. ${ }^{(2)}$ Chi-square test. ${ }^{(3)}$ Fisher's exact test. *Variables selected for logistic regression test.

$\mathrm{CHD}=$ congenital heart disease; $\mathrm{SD}=$ standard deviation

\section{DISCUSSION}

This study demonstrated that the current frequency of postnatal detection of CHD at our service is 5.3\%. The variables low $1^{\text {st }}$ min Apgar score, low birth weight, and CHD complexity were independent factors that affected hospital mortality.

Similar to previous studies, we established that the postnatal incidence of CHD is high at our center ${ }^{[21,22]}$ possibly due to the absence of laws that facilitate the interruption of gestation in Brazilian patients with $\mathrm{CHD}^{[9,15,17]}$. Moreover, patients are referred to a tertiary center after prenatal diagnosis, thereby increasing the incidence of CHD at our institute. Additionally, in the univariate analysis, the prenatal diagnosis was associated with death probably due to the same fact that our institution is tertiary. A study comparing the surgical results of between children with intrauterine diagnosis and postnatal diagnosis may clarify such finding.

The higher prevalence of "complex" and "significant" $\mathrm{CHD}$ can also be attributed to the fact that our hospital is a reference center for $\mathrm{CHD}$. Besides, the routine use of Doppler echocardiography has increased the diagnosis of "minor" defects (i.e., small ventricular septal defect, milder forms of pulmonary stenosis, and atrial septal defect) in asymptomatic children. In fact, some studies have reported a high frequency of ventricular septal defect ${ }^{[22]}$, as established in our study.

Reportedly, low birth weight is associated with increased mortality rate in patients admitted for heart surgery ${ }^{[23,24]}$. Remarkably, we determined that low birth weight was an independent risk factor for hospital mortality regardless of patients being admitted for surgery or not. In addition, other studies have established a correlation between prematurity and increased mortality rate, rather than low birth weight; however, such association was not determined in our analysis ${ }^{[25,26]}$. Low birth weight is also often associated with other major congenital anomalies, which might affect morbidity and mortality. Consequently, such cases are the most complicated and severe ones in the delivery room, presenting an increased risk of having a lower $1^{\text {st }}$ min Apgar score (other independent risk factors for mortality that were found).

Previous studies have reported early mortality rates ranging from $10 \%$ to $42 \%{ }^{[22,27]}$; however, studies that reported the lowest mortality rate included no patients with functionally univentricular physiology and all their patients could undergo surgery at a single stage ${ }^{[27]}$. The mortality rate of our patients admitted for heart surgery was 38\%, which could be attributed to the high complexity of heart diseases at our service (85\% of cases operated) with the majority of patients with functionally univentricular physiology. The mortality rate was slightly higher (66.7\%) in our study than the expected mortality rate $(47.7 \%)$ for RACHS risk 6 $6^{[20]}$. Probably, multifactorial causes justify our suboptimal results. The absence of ECMO in our institution ${ }^{[28]}$, as well as not measured aspects related to hospital infra-structure, human resources or children nutritional state may be associated. Despite of this, such results showed us that we need to improve the quality of the data collection in order to identify flaws during the preoperative, intraoperative and/or postoperative course.

However, our study had several drawbacks, many of which are attributed to the retrospective study design. Moreover, we did not collect the prenatal echocardiographic data and used the hospital mortality as an outcome. The lack of representative ambulatory data precluded comprehensive analysis of the 
prognosis. Furthermore, the absence of intraoperative and postoperative data as well as specific causes of the mortality prevented us from differentiating the primary cause of mortality.

\section{CONCLUSION}

In conclusion, this study reports that the postnatal incidence of $\mathrm{CHD}$ at our service was $5.3 \%$ and that low $1^{\text {st }}$ min Apgar score, low birth weight, and CHD complexity are independent factors, affecting hospital outcome. The results of this study could contribute to the development of policies that improve mortality rates.

\section{Authors' roles \& responsibilities}

LAR Writing and statistical analysis; final approval of the version to be published

SCF Collect data; final approval of the version to be published

CCS Collect data; final approval of the version to be published

SANF Critical review; final approval of the version to be published

JCSG Critical review; final approval of the version to be published

RG Supervision; final approval of the version to be published

EAJ Supervision; final approval of the version to be published

\section{REFERENCES}

1. Carvalho JS, Mavrides E, Shinebourne EA, Campbell S, Thilaganathan B. Improving the effectiveness of routine prenatal screening for major congenital heart defects. Heart. 2002;88(4):387-91.

2. Yu Z, Xi Y, Ding W, Han S, Cao L, Zhu C, et al. Congenital heart disease in a Chinese hospital: pre- and postnatal detection, incidence, clinical characteristics and outcomes. Pediatr Int. 2011;53(6):1059-65.

3. Ozbarlas N, Erdem S, Küçükosmanoğlu O, Seydaoğlu G, Demir C, Evrüke $C$, et al. Prevalence and distribution of structural heart diseases in high and low risk pregnancies. Anadolu Kardiyol Derg. 2011;11(2):125-30.

4. Lee JE, Jung KL, Kim SE, Nam SH, Choi SJ, Oh SY, et at. Prenatal diagnosis of congenital heart disease: trends in pregnancy termination rate, and perinatal and 1-year infant mortalities in Korea between 1994 and 2005. J Obstet Gynaecol Res. 2010;36(3):474-8

5. Friedberg MK, Silverman NH, Moon-Grady AJ, Tong E, Nourse J, Sorenson $\mathrm{B}$, et al. Prenatal detection of congenital heart disease. J Pediatr. 2009;155(1):26-31.

6. Clur SA, Van Brussel PM, Mathijssen IB, Pajkrt E, Ottenkamp J, Bilardo CM. Audit of 10 years of referrals for fetal echocardiography. Prenat Diagn. 2011;31(12):1134-40.

7. Galindo A, Herraiz I, Escribano D, Lora D, Melchor JC, Cruz J. Prenatal detection of congenital heart defects: a survey on clinical practice in Spain. Fetal Diagn Ther. 2011;29(4):287-95.

8. Friedberg MK, Silverman NH, Moon-Grady AJ, Tong E, Nourse J, Sorenson $\mathrm{B}$, et al. Prenatal detection of congenital heart disease. J Pediatr. 2009;155(1):26-31.

9. Garne E, Stoll C, Clementi M; Euroscan Group. Evaluation of prenatal diagnosis of congenital heart diseases by ultrasound: experience from 20 European registries. Ultrasound Obstet Gynecol. 2001;17(5):386-91.
10. DolkH, Loane M, Garne E; European Surveillance of Congenital Anomalies (EUROCAT) Working Group. Congenital heart defects in Europe: prevalence and perinatal mortality, 2000 to 2005. Circulation. 2011;123(8):841-9.

11. Caneo LF, Jatene MB, Yatsuda N, Gomes WJ. A reflection on the performance of pediatric cardiac surgery in the State of São Paulo. Rev Bras Cir Cardiovasc. 2012;27(3):457-62.

12. Araujo Júnior E, Rolo LC, Nardozza LM, Moron AF. Fetal cardiac evaluation by 3D/4D ultrasonography (STIC): what is its real applicability in the diagnosis of congenital heart disease? Rev Bras Cir Cardiovasc. 2013;28(1):III-V.

13. Allan L. Prenatal diagnosis of structural cardiac defects. Am J Med Genet C Semin Med Genet. 2007;145C(1):73-6.

14. Bull C. Current and potential impact of fetal diagnosis on prevalence and spectrum of serious congenital heart disease at term in the UK. British Paediatric Cardiac Association. Lancet. 1999;354(9186):1242-7.

15. Hoffman JI. Incidence of congenital heart disease: II. Prenatal incidence. Pediatr Cardiol. 1995;16(4):155-65.

16. Souza AH, Fonseca L, Franchi SM, Lianza AC, Baumgratz JF, Silva JP. The hypoplastic left heart syndrome is not a risk factor for Fontan operation. Rev Bras Cir Cardiovasc. 2010;25(4):506-9.

17. Rocha LA, Araujo Júnior E, Rolo LC, Barros FS, Silva KP, Leslie AT, et al. Prenatal detection of congenital heart diseases: one-year survey performing a screening protocol in a single reference center in Brazil. Cardiol Res Pract. 2014;2014:175635.

18. Hunter S, Heads A, Wyllie J, Robson S. Prenatal diagnosis of congenital heart disease in the northern region of England: benefits of a training programme for obstetric ultrasonographers. Heart. 2000;84(3):294-8.

19. Wren C, Richmond S, Donaldson L. Temporal variability in birth prevalence of cardiovascular malformations. Heart. 2000;83(4):414-9.

20. Jenkins KJ, Gauvreau K, Newburger JW, Spray TL, Moller JH, lezzoni LI. Consensus-based method for risk adjustment for surgery for congenital heart disease. J Thorac Cardiovasc Surg. 2002;123(1):110-8.

21. Reller MD, Strickland MJ, Riehle-Colarusso T, Mahle WT, Correa A. Prevalence of congenital heart defects in metropolitan Atlanta, 19982005. J Pediatr. 2008;153(6):807-13.

22. Holland BJ, Myers JA, Woods CR Jr. Prenatal diagnosis of critical congenital heart disease reduces risk of death from cardiovascular compromise prior to planned neonatal cardiac surgery: a meta-analysis. Ultrasound Obstet Gynecol. 2015;45(6):631-8.

23. Curzon CL, Milford-Beland S, Li JS, O'Brien SM, Jacobs JP, Jacobs ML, et al. Cardiac surgery in infants with low birth weight is associated with increased mortality: analysis of the Society of Thoracic Surgeons Congenital Heart Database. JThorac Cardiovasc Surg. 2008;135(3):546-51.

24. Kalfa D, Krishnamurthy G, Duchon J, Najjar M, Levasseur S, Chai P, et al. Outcomes of cardiac surgery in patients weighing $<2.5 \mathrm{~kg}$ : affect of patient-dependent and -independent variables. J Thorac Cardiovasc Surg. 2014;148(6):2499-506.

25. Costello JM, Polito A, Brown DW, McElrath TF, Graham DA, Thiagarajan RR, et al. Birth before 39 weeks' gestation is associated with worse outcomes in neonates with heart disease. Pediatrics. 2010;126(2):277-84.

26. Costello JM, Pasquali SK, Jacobs JP, He X, Hill KD, Cooper DS, et al. Gestational age at birth and outcomes after neonatal cardiac surgery: an analysis of the Society of Thoracic Surgeons Congenital Heart Surgery Database. Circulation. 2014;129(24):2511-7.

27. Ades AM, Dominguez TE, Nicolson SC, Gaynor JW, Spray TL, Wernovsky $\mathrm{G}$, et al. Morbidity and mortality after surgery for congenital cardiac disease in the infant born with low weight. Cardiol Young. 2010;20(1):8-17.

28. Conrad SJ, Bridges BC, Kalra Y, Pietsch JB, Smith AH. Extracorporeal cardiopulmonary resuscitation among patients with structurally normal hearts. ASAIO J. 2017;63(6):781-6. 